\title{
Pendidikan Islami "Antara Cita dan Fakta"
}

Muzhoffar Akhwạan, Imam Syafi'ie, M.A. Fattah Santoso, Muhaimin

Muzhoffar Akhwan, lahir 9 Agustus 1954, alumni Fakultas Filsafat UGM tahun 1966, adalah dosen Fakultas Tarbiyah UII Yogyakarta.

Imam Syafi'ie, lahir 6 Agustus 1954, alumni Fakultas Tarbiyah IAIN Sunan Kalijaga tahun 1980. adalah dosen Fakultas Tarbiyah UII Yogyakarta mulai tahun 1984 s.d. sekarang.

M.A. Fattah Santono, lahir

8 Aguistus 1954, alumni IKIP Malang tahun 1981, dosen UMS Surakarta múlai tahun 1982 s.d. sekarang adalah Direktur Pondok Shobron UMS Surakarta.

Múhaimin, adalah alumni Fakultas Tarbiyah IAIN Sunan Ampel Malang dạn sebagai dösen pada Faǩultas yang sama.

\section{PENDAHULUAN}

Bentuk dan sistem pendidikan Islami sebagaimana berlaku dalam kehidupan masyarakat kini, secara historis merupakan hasil kumulatif perjuangan yang terus menerus dari para 'tokoh dan pejuang pendidikan kita. Tanpà mengurangi penghargaan akan jasa dari pendahulu tersebut, kita masih menyáksikan kenyataan bahwa pendidikan Islami yang áda sampai saat ini masih menampakkan berbagai permasalahan berat dan sérius yang memerlukan penanganan.

'Dorongan untuk menemukan pemecahan terhadap berbagai permasalahan yang muncul tidak saja' berasal dari kebutuhan subjektif untuk makin meningkatkan mutu pendidikan Islami yang diselenggarakan, tetapi juga oleh tuntutan perkembangan 'masa depan masyarakat kita dalam rangka menyiapkan' generasi yang berkulitas. 'Senada dengan pesan Illahi :

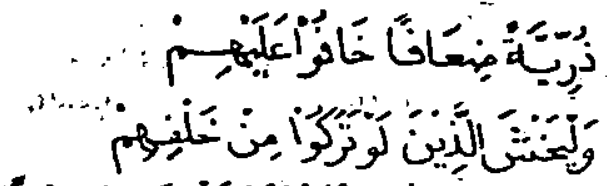

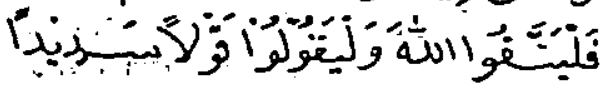

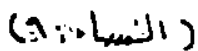

"Hendaklah mereka cemas seandainya di belakang mereka meninggalkan suatu generași yang lemah (baik jasmaniah maupun 
rohaniah) yang mereka khawatirkan nasibnya" (Q.S. Al Nisa : 9).

Dan wasiat Nabi Muhammad S.A.W. :

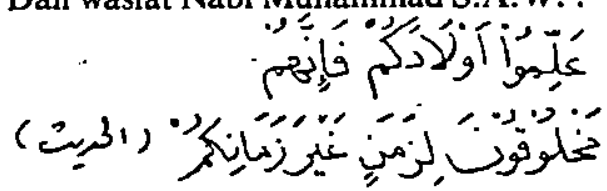

"Didiklah anak-anakmu, karena sesungguhnya mereka diciptakan untuk zamannya dan bukan untuk zamanmu" (al-hadits).

Sehubunan dengan itu, artikel ini mencoba mengidentifikasi berbagai permasalahan utama yang dihadapi oleh pendidikan Islami yang seharusnya. Kesenjangan antara realita pendidikan Islami dan cita pendidikan Islami dijembatani oleh beberapa alternatif pemecahan.

\section{IDENTIFIKASI MASALAH PENDIDIKAN ISLAMI}

1. Pandangan dikotomis yang memisahkan ilmu-ilmu agama dan ilmuilmu umum. Pandangan ini telah melahirkan tiga lembaga pendidikan :

\subsection{Sekolah Umum yang menitik- beratkan pada pengkajian ilmu- ilmu umum; \\ 1.2. Pesantren yang menitikberatkan pada pengkajian ilmu-ilmu aga- ma;}

1.3. Madrasah yang menitikberatkan pada pengkajian ilmu-ilmu agama;

2. Ambivalensi orientasi pendidikan Islami tercermin pada kenyataan, bahwa :

2.1. Pesantren lebih berorientasi pada penyiapan menuasia taqwa dalam pengertian sempit yang mengabaikan pemberian bekal untuk menjalankan fungsinya sebagai khalifah di muka bumi.
2.2. Sekolah umum yang lebih berorientasi pada penguasaari disiplin ilmu-ilmu umum dan ketrampilan yang diperlukan untuk memerankan fungsi khalifah di muka bumi, tanpa dasar pijakan yang kuat dan nilai-nilai agama.

2.3. Madrasah yang tidak lagi berorientasi pada tujuan Islam (membentuk manusia taqwa) dan juga tidak mencapai tujuan pendidikan sekolah umum.

3. Kesenjangan antara ajaran Islam dan sistem ajaran Islam.

Kesenjangan ini dapat dilihat dengan adanya kenyataan :

3.1. Tujuan pendidikan Islam lebih diarahkan pada penghayatan taqwa yang menekankan segisegi kepatuhan, yang pusat pencarian makna hidupnya lebih diwujudkan dalam kesalehan individual yang mangacu kepada ridla Allah lewat intensitas ritual.

3.2. Fungsi pendidikan Islami lebih ditekankan pada pewarisan nilai atau penanaman keagamaan hasil internalisasi generasi tertentu yang lebih bersifat kontekstual, sehingga menjadi kurang relevan untuk menjawab tantangan dunia' modern dan kalaupun toh jawaban itu ada, maka ia masih bersifat apalogetik.

3.3. Metode lebih bersifat verbalistik, sehingga dinidik tidak diajak melakukan refleksi teologis dalam rangka merespons setiap

. bentuk dan gejala dalam realitas yang dihadapinya. 
3.4. Materi yang menitikberatkan pada hubungan manusia dengan Allah (ibadah dalam arti khusus) dan belum mengintegrasikan problematik empirik di sekitar dihidik. (M. Abdurrahman, 1987, 10-18; S.I. Santoso, 1985).

4. Integrasi pendidikan Islami dalam penelitian nasional.

Dikaitkan dengan pendidikan nasional, bagaimanapun, pendidikan Islami dituntut ikut menunjang tercapainya tujuan pendidikan nasional sebagaimana dirumuskan dalam GBHN (Tap. MPR No. 11/1988) yang berbunyi : "Meningkatkan kualitas manusia Indonesia, yaitu manusia yang berbudi luhur, berkepribadian, berdisiplin, bekerja keras, tangguh, bertanggung jawab, mandiri, cerdas dan trampil serta sehat jasmani dan rohani; pendidikan nasional juga harus mampu menumbuhkan dan memperdalam rasa cinta tanah air, mempertebal semangat kebangsaan dan rasa kesetiakawanan sosial. Sejalan dengan itu dikembangkan iklim belajar dan mengajar yang dapat menumbuhkan rasa percaya pada diri sendiri serta sikap dan prilaku yang inovatif dan kreatif; dengan demikian pendidikan nasional akan mampu mewujudkan manusia-manusia pembangunan yang dapat membangun dirinya sendiri serta bersama-sama bertanggung jawab atas pembangunan bangsa ${ }^{n}$.

Memenuhi tuntutan yang terdapat dalam tujuan pendidikan nasional tersebut, ada kelemahan yang dirasakan dalam pelaksanaan pendidikan Islami, antara lain : belum menyiapkan dinidik yang memiliki ciri manusia taqwa yang relevan bagi pembangunan bangsa seperti kepedulian sosial, kearifan, demokratis, dan toleransi pada kemajemukan.

\section{CITA PENDIDIKAN ISLAMI (DAS SOLLEN)}

Cita pendidikan Islami adalah menghantarkan dinidik memperoleh ridla Allah dalam kehidupan dunia dan akhirat melalui pengembangan sikap hidup penuh ketaqwaan, agar dapat menumbuhkan pribadi-pribadi utama (insan kamil) yang dapat membangun dirinya sendiri serta bersama-sama bertanggung jawab sebagai khalifah di muka bumi (Q.S. Mąryam : 5 - 6; alBaqarah : 201 ; Al-A'raf : 26; al-Hujurat : 13; al-Baqarah : 30; Hud : 61).

Adapun profil pribadi utama (insan kamil) yang dikehendaki adalah antara lain : (1) mengabdi kepada kebenaran (Q.S. al-Baqarah : 42; Maryam : 12); (2) menjaga kemuliaan sebagai makhluk yang berakal dan dimuliakan (Q.S. alMulk : 10; al-Anfal : 4; Al-Isra' : 170) ; (3) kreatif yang menumbuhkan gagasan baru bagi kemanusiaan (Q. S. alNahl : 97; Alam Nasyrah : 78) ; (4) mendahulukan prestasi kerja dan pengabdian daripada prestise (Q. S. Al-An'am : 132; Al-Nahl : 97); (5) monokotomis yang menumbuhkan integralisme sistem Ilahiah ke dalam sistem insaniah dan sistem kauniyah (Q. S. al-An'am : 162); (6) memiliki kearifan yang menghasilkan pengambilan kepututsan yang tepat (Q. S. Maryam 12); (7) memiliki kasih sayang yang menumbuhkan karakter dan aksi solidaritas (Q. S. Maryam : 13; al-Fath : 29); (8) berbakti kepada orang tua (Q. S. Luqman : 14; al-Isra' : 24 ; Maryam : (14); (9) memiliki kasih sayang ter- 
hadap isteri dan anak (Q. S. al-Furqan : 74; al-Rum : 21); (10) memiliki kesucian hati yang menumbuhkan kesabaran, amanah, kejujuran, keikhlasan serta tidak riya', tidak sombong (Q. S. Maryam : 13; al-Syuara' : 87 - 89; Luqman : 17 - 19); (11) berorientasi ke masa depan (Q. S. al-Hasyr : 18); (12) penuh optimisme (Q. S. al-Zumar : 53); (13) memilki rasa kekeluargaan dan persaudaraan (ukhuwah) yang menumbuhkan sikap egaliter (Q. S. alHujurat : 10 - 13); (14) ta'awun (altruistik) (Q. S. al-Ma' idah : 2); (15) bersikap demokratis yang menumbuhkan rasa penghargaan dan penghormatan terhadap persepsi yang berbeda (Q. S. al-Syura : 38; Ali-lmran : 159; alBaqarah : 139; al-Kafirun : 6); (16) memiliki rasa keadilan yang menumbuhkan persamaan hak serta perolehan (Q. S. al-Ma'idah : 8); (17) memilki disiplin yang menumbuhkan keteraturan dan ketertiban dalam kehidupan (Q. S. al-'Ashr : 1 - 3; Fushshilat: 30); (18) memiliki intelektual (terpelajar) yang menumbuhkan daya imaginasi dan daya cipta (Q. S. al-Mujadilah : 11); (19) penuh kesederhanaan yang menumbuhkan rasa dan karsa menjauhkan diri dari pemborosan dan kemubadziran (Q. S. al-A'raf : 31; al-Isra' : 26 - 27); (20) bercahaya yang menumbuhkan jalan terang bagi lingkungannya (amar ma' ruf nahi munkar) (Q. S. Ali-Imran : 110 dan 104).

\section{ALTERNATIF PEMECAHAN}

Pemecahan dengan ide baru melalui sistem dan kondisi yang ada.

Untuk bentuk pemecahan ini, pengembangan pendidikan Islami mengikuti dua jalur : sekolah umum dan Madrasah/pesantren. Madrasah dan pe- santren berada dalam satu jalur, mengingat banyaknya pesantren yang menerapkan sistem madrasah dalam penyelenggaraan pendidikannya.

Pada masing-masing jalur memperoleh basis ilmu yang sama, baik di bidang ilmu agama maupun ilmu umum. Basis ilmu ini diberikan dari jenjang terendah (Taman Kanak-kanak) sampai dengan tingkat menengah atas (SMA/Aliyah).

Basis ilmu ini bersifat fardlu ain dan dalam gambar tercermin pada gambar segitiga $A B C$ jenjang berikutnya adalah :

a. Perguruan tinggi umum yang tercermin dalam segitiga DCF merupakan spesialisasi ayat kauniyah mulai dari program $\mathrm{S}^{0}, \mathrm{~S}^{1}, \mathrm{~S}^{2}, \mathrm{~S}^{3}$.

b. Ma'had 'Ali atau perguruan tinggi agama yang tercermin dalam segitiga CEG merupakan spesialisasi ayat tanzili mulai dari santri, mu'allim, ustadz atau kiyai. Kedua jenjang spesialisasi ini dianggap fardlu kifayah.

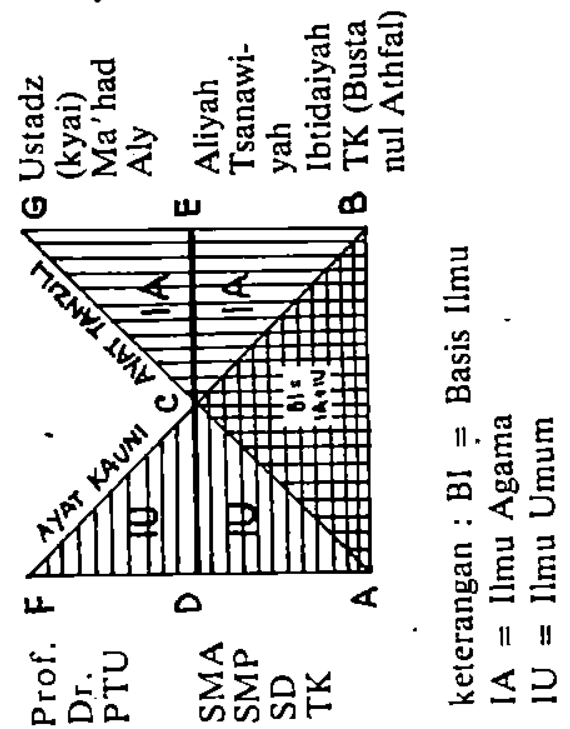


(A. M. Saifuddin, et. al., 1987. p. 100 - 101).

Fardlu ain diartikan sebagai basis ilmu yang wajib diketahui oleh calon intelektual dan calon ustadz (kiyai), sedangkan fardlu kifayah diartikan boleh dipilih oleh dinidik menurut keperluan umat seperti bidang ilmu kedokteran, fisika, hadits, tafsir dan - sebagainya.

Untuk mengembangkan basis ilmu di atas, perlu diperjelas tentang ontologi dan epistimologi dan aksiologi pendidikan Islami dalam rangka pengembangan kurikulumnya.

Dari segi ontologi, jlmu pengetahuan di dalam pendidikan Islami walaupun meliputi berbagai disiplin atau cabang ilmu, tetap merupakan kesatuan yang fokusnya sama, yaitu menjadikan manusia cinta kepada Allah, taqwa kepada Allah. Ilmu dalam pengertian ini adalah ilmu Allah (Q. S. Hud : 14) yang sama sekali tidak memisahkan antara ilmu agama dan ilmu umum sebagaimana tuntunan do'a dalam kerangka penambahan ilmu (Q.S. Thaha : 114). Dari sumber pokok ilmu Allah inilah lalu mengalir berbagai disiplin ilmu melalui saluran-salurannya, ibarat sebuah pohon dengan berbagai cabang, dahan dan rantingnya. Tiga sumber pokok yang menjadi landasan perumusan ilmu adalah alQur'an, sunnah Rasul dan alam semesta (Q. S. al-Baqarah : 2; 147; Ali-Imran : 190; Al-Qalam : 4).

Dari ketiga sumber itulah diturunkan berbagai disiplin ilmu yang pada hakekatnya satu kesatuan yakni ilmu Allah yang paling tidak mencakup al-Din, sains danteknologi. Dengan ilmu Allah itu, kita dirangsang untuk menukik dan melihat dengan lebih tajam ufuk-ufuk atau cakrawla luar yang luas atau makro kosmos (Q. S. Fush-shilat: 53 "Sanurihim ayatina fil afaqi) lalu menghunjam dalam cakrawala yang lebih dalam atau mikro kosmos (wa fi anfusihim). Hal ini merupakan petunjuk agar kita melihat kepada alam di luar diri kita dulu, kemudian ke alam yang lebih dalam dan adä pada diri kita.

Artinya mustahil kita memilah-milahkan hal yang objektif dari yang subjektif dalam interaksi menggeluti kebenaran dengan perkataan lain tubuh ilmu merupakan refleksi objektif positif sekaligus subjektif normatifnya. Pandangan kesemestaan ilmu tersebut merupakan dataran operasional untuk menyususn organisasi kurikulum . (A. M. Saifuddin, 1987, p.

Sedangkan dari segi epistimologi, ilmu pengetahuan tersebut di atas didekati melalui strategi dan metode pendidikan berikut :

Darisegi strategi isi pendidikan dapat didekati secara partial dan intergal. Secara partial artinya pendidikan menumbuhkan qalb dan $a q l$, sedangkan secara integral artinya pendidikan menumbuhkan dan melestarikan nilai mulia dan akhlak terpuji. Pertumbuhan qalb, aql dan akhlak terpuji yang ketiganya berinteraksi dan konsisten, hendaknya selain berwawasan makro kosmos dan mikro kosmos, juga berwawasan masa depan yang panjang, yakni masa depan problematik global dan krisis global yang berasal dari sejumlah kecenderungan multi dimensional sebagai berikut : (1) meningkatnya pengaruh lingkungan terhadap aktifitas manusia; (2) makin sedikitnya 
sumber-sumber yang dapat dilestarikän; (3) peningkatan eksponential penduduk dunia; (4) masalah-masalah peningkatan produksi pangan untuk mencukupi kebutuhan penduduk dunia; (5) meningkatnya klecenderungan kepada modernisasi dan indutrialisasi dari ! hampir seluruh aktifitas manusia; (6) meningkatnya kecenderungan pada urbanisasi dan tumbuh suburnya megalopolis; (7) melebarnya jurang antara negara-negara maju dengan negara-negara sedang berkembang; (8) meningkatnya keberuntungan kepada teknologi; (9) meningkatnya kecenderungan budaya inderawi yang bersifat empiris, sekular, duniawi, humanistik, pragmatik, utiliter, dan hedonistik; (10) meningkatnya pengangguran/kekurangan lapangan kerja; (11) pembaharuan yang dirangsang timbulnya bukan oleh adanya kebutuhan riil. tetapi oleh semakin besarnya ketidakseimbangan konsumsi;; (12) meningkatnya keterpisahan dari alam, keterasingan manusia dari dirinya sendiri, dari sesama manusia, dari alam lingkungannya dan keterasingan manusia dari Allah. (Zainuddin Sardar, 1986, 100 - 102).

Sedangkan metode pendidikan Islami, berbeda' dengan strategi, merupakan alternatif prosedur. Memilihmilih alternatif prosedur yang tepat hendaknya didasarkan pada pertimbangan tujuan instruksional yang ingin dicapai dan pada karakteristik materi isi yang dipelajari atau pada karakteristik dinidiknya sendiri, dan dimungkinkan untuk memilih lebih dari satu metode (multi metode). Metode pendidikan yang paling efektif untuk memproleh informasi optimal ialah metode ceramah,' sedangkan untuk mendapatkan persepsi fuktual yang lebih jelas, maka metode demonstrasi, observasi dan eksperimental merupakan pilihan yang baik. Untuk memperoleh kemampuan yang tinggi dalam analisis, sintesis dan evaluasi yang dapat melahirkan kreatifitas, maka multi metode dari metode diskusi, kerja/studi kelompok dan studi mandiri merupakan pilihan yang tepat, sedangkan untuk membantu meningkatkan ketrampilan, metode kerja lapangan, kerja kelompok eksperimen merupakan pilihan metode yang banyak membantu. Dan untuk mencapai pembinaan akhlak terpuji, maka metode imitasi/contoh atau model, diskusi bebas dan metode konsultasi adalah metode-metode pilihan yang baik akan menghasilkan kejujuran, amanah, disiplin, kerja keras dan sifatsifat terpuji lainnya dari manusia taqwa (A. M. Saifuddin, 1987, p. 129.

Taqwa kepada Allah, mencari ridla Allah, inilah indikator keberhasilan pendidikan manusia seutuhnya. Taqwa adalah cinta kepada Allah, sedangkan cinta itu menumbuhkan motivasi positif dan kreatifitas tinggi. Taqwa adalah iman kepada Allah, yang menumbuhkan karakter rendah hati dan penuh optimistik. Juga taqwa adalah takut dan taat kepada Allah yang menumbuhkan karakter berani dan tanggung jawab. Taqwa juga adalah sebuah bangunan tumpuan aksiologi pendidikan. Pendeknya kita dapat mengatakan bahwa di dalam diri manusia seutuhnya yang taqwa kepada Allah terdapat keutuhan berbagai karakter atau tingkah laku yang penuh dengan nilai atau etos, sarat dengan manfaat atau etis dan keindahan atau eset is sebagaimana yang diinginkan dalam tujuan pendidikan nasional di Indonesia. 


\section{FAKTOR PENUNJANG DAN PENGHAMBAT}

Alternatif pemecahan yang telah diuraikan di atas memiliki beberapa faktor pendukung, seperti :

1. Sila pertama Pancasila, Ketuhanan Yang Maha Esa, yang menjadi landasan bagi.sila-sila linnya.

2. Tujuan pendidikan nasional yang tertuang dalam Tap. MPR No. II/MPR/1988 tentang GBHN

3. SKB Tiga Menteri (Menteri Agama, Menteri Pendidikan dan Kebudayaan dan Menteri Dalam Negeri) tahun 1975 yang mencerminkan kerjasama antar para pengelola pendidikan di Indonesia.

4. Kondisi sosio-psikologis bangsa Indonesia yang dengan hidup kesela- . rasannya menerima perubahan yang itdak bersifat revolusioner.

Dengan beberapa faktor pendukung di atas, bukan berarti alternatif pemecahan ini tanpa penghambat. Adapun faktor-faktor penghambatnya antara lain :

1. Adanya visi pandangan sebagian besar pelaksanaan pendidikan yang masih dikotomis.

2. Perbedaan porsi alokasi anggaran antara Departemen-Departemen yang mengelola pendidikan.

\section{DAFTAR PUSTAKA}

A. M. Saifuddin, et: al., Desekularisasi $\rightarrow$ Pemikiran : Landasan Islamisasi. Bandung : Mizan, 1987.

Moeslim Abdurrahman,' Pendidikan Agama yang Membebaskan, ${ }^{\prime}$ dalam "PESANTREN", No. 2/Vol.IV/1987.

Slamet Iman Santosa, Muhaimin, Imam Syafei, Mudzoffar Akhwan, Rumusan Tujuan Pendidikan Islami, Tugas Terstruktur V dalam Mata Kuliah "Pèngembangan Kurikulum", Fakultas Pasca Sarjana IAIN Sunan Kalijaga Yogyakarta, April 1988.

M. A. Fattah Santoso, 'Pendidikan Agama yang Reflektid Dalam Pembangunan Bangsa Yang Berparadigma Transformasi, 'dalam : "AKADEMIKA", No. 06, Th. VI, Januari 1988.

Zianuddin. Sardar, Rekayasa Masa Depan Peradaban Muslim. Bandung : Mizan, 1986.

TAP MPR 88. Surakarta : Pabelan, 1988.

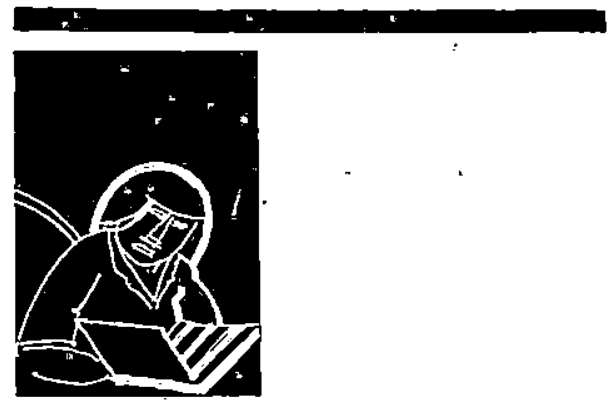

